\title{
ПРИМЕНЕНИЕ ЭКОНОМИЧЕСКОГО МЕХАНИЗМА КАК МЕТОД СНИЖЕНИЯ ПОЖАРНОГО РИСКА
}

\section{THE USE OF AN ECONOMIC MECHANISM AS A METHOD OF REDUCING FIRE RISK}

\section{O. Kruzhkova}

E. Kuznetsova

Summary. The purpose of the study is to analyze the application of the financial mechanism of insurance in order to redistribute potential economic damage in the event of a fire.

In this article, based on the methods of analysis and comparison, it was proposed to improve the integration processes in the field of fire insurance of housing, to create an effective motivation system for policyholders, to increase the favorable climate for new investments, which explains the relevance of the study.

Keywords: fire risk, economic mechanism, fire insurance, economic damage from fire.

\author{
Кружкова Ольга Владимировна \\ К.э.н., доцент, Академия ГПС МЧС России, г. Москва \\ olga_k_v@list.ru \\ Кузнецова Екатерина Сергеевна \\ K.т.н., дочент, Академия ГПС МЧС России, г. Москва \\ ekuzn25@yandex.ru
}

Аннотация. Целью исследования является анализ применения финансового механизма страхования с целью перераспределения потенциального экономического ущерба при возникновении пожара.

В данной статье на основе методов анализа и сравнения было предложено усовершенствовать интеграционные процессы в сфере противопожарного страхования жилья, создать эффективную систему мотивации для страхователей, повысить благоприятный климат для новых инвестиций, что объясняет актуальность исследования.

Ключевые слова: пожарный риск, экономический механизм, противопожарное страхование, экономический ущерб от пожара.

Экономические методы, как правило, реализуются посредством страхования и совместного страхования рисков, штрафных санкций, реализации квот на уровень пожарного риска.

Социально-психологические методы направлены на формирование общественного мнения вокруг проблемы пожарной безопасности, воспитания в русле ответственности за собственную безопасность, обучение пожаробезопасному поведению и т.д.

В России наиболее эффективно применяют административные и социально-психологические методы управления пожарным риском, экономические методы развиты гораздо слабее. Вместе с тем, именно эта группа методов позволяет воздействовать на показатель размера материального ущерба от пожара, который на территории Российской Федерации, несмотря на предпринимаемые меры на протяжении последних лет демонстрирует рост как общего показателя, так и показателя размера ущерба от крупных пожаров (табл. 1). [2]

В среднем прямой ущерб от пожаров для всех стран оценивается в 0,21\% валового национального продукта (ВНП), косвенный - 0,04\% (в 5 раз меньше прямого). 
Таблица 1. Этапы управления пожарным риском

\begin{tabular}{|l|l|l|l|l|l|}
\hline Анализ риска & $\square$ & $\begin{array}{l}\text { Выбор методов } \\
\text { воздействия на риск }\end{array}$ & $\begin{array}{l}\text { Принятие решения, } \\
\text { оказывающее воздействие } \\
\text { на риск }\end{array}$ & $\mathbf{W}$ \\
\hline
\end{tabular}

Таблица 2. Методы управления пожарным риском

\begin{tabular}{|c|c|c|}
\hline Административные методы & Экономические методы & $\begin{array}{l}\text { Социально-психологические } \\
\text { методы }\end{array}$ \\
\hline $\begin{array}{l}\text { разработка и контроль противопожарных } \\
\text { требований }\end{array}$ & перераспределения риска & морального воздействия \\
\hline создание и содержание пожарной охраны & экономической ответственности & психологического воздействия \\
\hline лицензирование & экономического стимулирования & \\
\hline сертификация & рыночные механизмы регулирования риска & \\
\hline \multicolumn{3}{|l|}{ безвозмездное финансирование } \\
\hline \multicolumn{3}{|l|}{ целевые программы } \\
\hline прочие & & \\
\hline
\end{tabular}

\section{Экономическая эффективность $=\frac{\text { прямой эффект }}{\text { затраты }}$}

Рис. 1. Формула экономической эффективности реализации предлагаемых мероприятий

Содержание пожарной охраны составляет 0,16\% ВНП, противопожарная защита зданий - 0,28\% и содержание страховых компаний - 0,11\%. В целом для 20 развитых стран потери от пожаров достигают 0,25\% ВНП, затраты на борьбу с ними - 0,57\% ВНП, т.е. затраты больше потерь почти в 3 раза. В среднем суммарная «стоимость» пожаров в этих 20 странах составляет 0,8\% ВНП. Если к этому добавить социальные потери, связанные с гибелью и травмированием людей, затраты на научные исследования, подготовку кадров для пожарной охраны и т.п., то «стоимость» пожаров достигнет примерно 1-2\% ВНП. [1,5]

Предлагается для повышения защищенности личности и территории от пожарной опасности формировать фонд предупредительных мероприятий при внедрении противопожарного страхования, средства которого будут направляться на содержание добровольной пожарной охраны и обеспечение профилактических мероприятий. [2]

Необходимо учесть экономическую эффективность предлагаемых мероприятий (рис. 1).

Прямой эффект - это экономия от реализации мероприятия, которая возникает в случае внедрения более оптимальных (менее затратных) технических, ор- ганизационных решений. При расчете экономической эффективности необходимо учитывать фактор времени с помощью метода дисконтированного потока стоимости и определение чистого дисконтированного потока стоимости. [3]

На основе статистических данных, экспертных оценок и методов построения статистических прогнозов определяются система и значения базовых и прогнозируемых целевых показателей по программному и инерционному сценариям развития ситуации в области пожарной безопасности (табл. 3).

С этой целью определяется экономический эквивалент одной единицы каждого из используемых целевых показателей с применением экспертных, статистических и расчетных методов, характеризующий среднестатистические материальные и людские потери (рис. 2).

Под экономическим эквивалентом 1 погибшего $\left(Э_{2}\right)$ понимается возмещение, которое должны получить родственники погибшего в результате пожара. Оценка экономического эквивалента человеческой жизни, включающего оценку полученного образования, способность к труду и созданию определенных материальных или духовных ценностей, цену поддержания здоровья и другое, в зависимости от возраста человека 
Таблица 3. Показатели базовых и прогнозируемых целевых показателей по программному и инерционному сценариям развития ситуации в области пожарной безопасности [3]

\begin{tabular}{|c|c|c|}
\hline Показатель & Пояснение & Формула \\
\hline $\begin{array}{l}П_{c н} \text { - количество } \\
\text { зарегистрированных пожаров }\end{array}$ & $\begin{array}{l}\text { разница между количеством зарегистрированных пожаров, } \\
\text { определяемым по инерционному (ин) и программному (пр) } \\
\text { сценариям по каждому году реализации мероприятий }\end{array}$ & $\begin{array}{l}\Pi_{c u}=\Pi_{u н}-\Pi_{n p} \\
\text { (снижение показателя) }\end{array}$ \\
\hline $\begin{array}{l}\Gamma_{c н}-\text { количество погибших людей } \\
\text { при пожарах» }\end{array}$ & $\begin{array}{l}\text { разница между количеством погибших людей при пожарах, } \\
\text { определяемым по инерционному и программному сценариям }\end{array}$ & $\begin{array}{l}\Gamma_{c h}=\Gamma_{u н}-\Gamma_{n p} \\
\text { (снижение показателя) }\end{array}$ \\
\hline $\begin{array}{l}\mathrm{T}_{c н} \text { - количество населения, } \\
\text { получившего травмы при пожарах }\end{array}$ & $\begin{array}{l}\text { разница между количеством населения, получившим травмы } \\
\text { при пожарах, определяемым по инерционному и программному } \\
\text { сценариям }\end{array}$ & $\begin{array}{l}\mathrm{T}_{c u}=\mathrm{T}_{u н}-\mathrm{T}_{n p} \\
\text { (снижение показателя) }\end{array}$ \\
\hline $\begin{array}{l}P_{c н} \text { - размер экономического } \\
\text { ущерба }\end{array}$ & $\begin{array}{l}\text { разница между экономическим ущербом от пожаров, } \\
\text { определяемым по инерционному и программному сценариям }\end{array}$ & $\begin{array}{l}\mathrm{P}_{c н}=\mathrm{P}_{u н}-\mathrm{P}_{u н} \\
\text { (снижение показателя) }\end{array}$ \\
\hline $\begin{array}{l}\mathrm{C}_{c н}-\text { количество спасенных при } \\
\text { пожарах }\end{array}$ & $\begin{array}{l}\text { разница между количеством спасенных при пожарах, } \\
\text { определяемым по программному и инерционному сценариям }\end{array}$ & $\begin{array}{l}\mathrm{C}_{c н}=\mathrm{C}_{n p}-\mathrm{C}_{u н} \\
\text { (увеличение показателя) }\end{array}$ \\
\hline
\end{tabular}

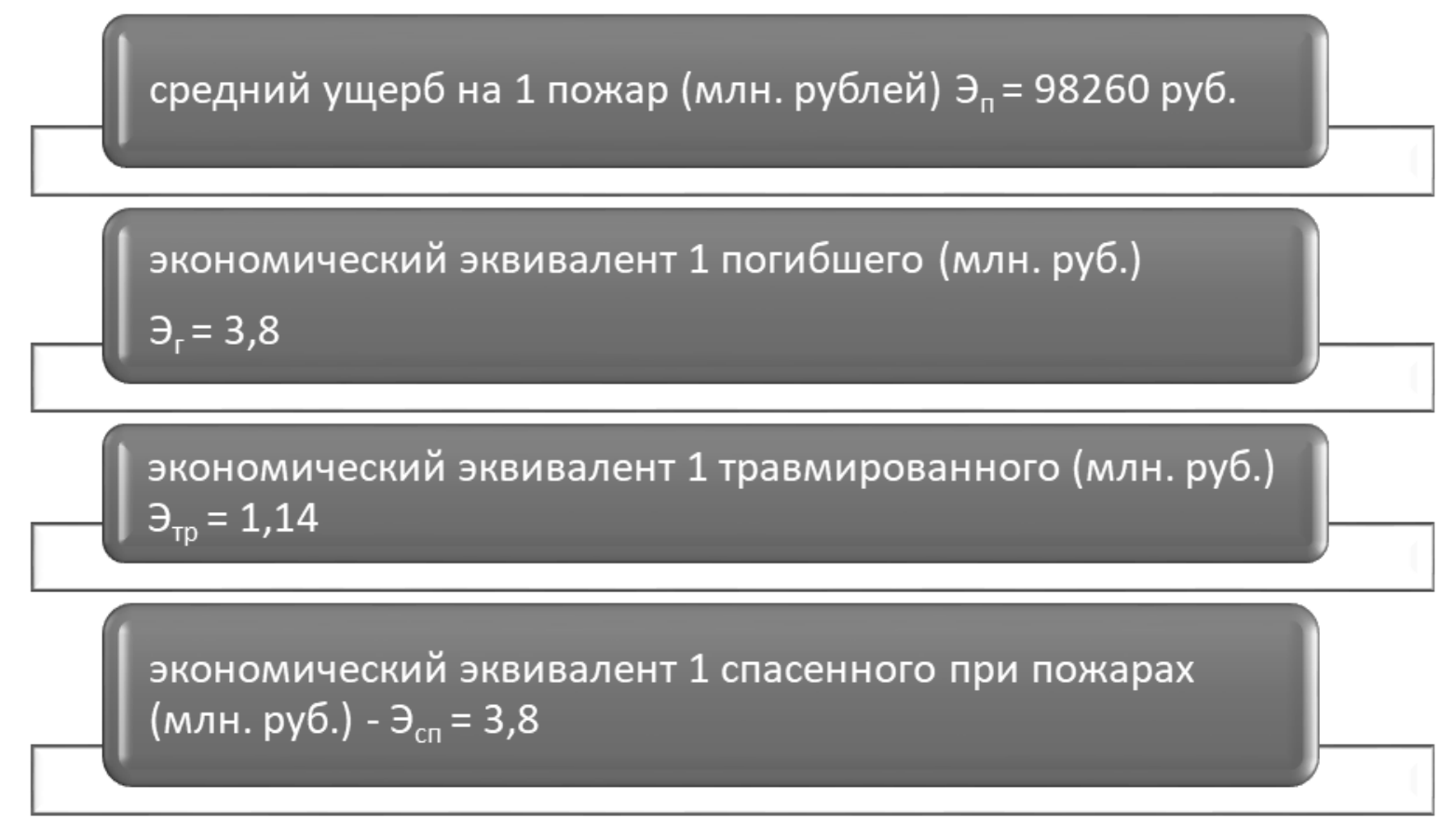

Рис. 2. Экономические показатели для расчета эффективности внедрения противопожарного страхования

составляет в среднем 3-4 млн. рублей. В расчетах принята величина 3,8 млн. рублей на 1 погибшего. [4]

Под экономическим эквивалентом 1 травмированного $\left(Э_{m p}\right)$ понимается соответственно возмещение, которое должен получить человек при потере здоровья в результате пожара. Поправочный коэффициент $=0,3$. В расчетах принята величина 1,14 млн. руб. на 1 травмированного.

Под экономическим эквивалентом 1 спасенного $\left(\ni_{c n}\right)$ понимается возможный вклад спасенного челове- ка в развитие экономики государства. В расчетах принята величина, равная 3,8 млн. рублей на 1 спасенного.

Расчет бюджетной эффективности мероприятий производится аналогично порядку расчета ее социально-экономической эффективности.

При определении результатов предлагаемых решений учитываются следующие экономические составляющие:

- прямой финансовый вклад в валовой внутренний продукт; 
- репродуктивный и культурный вклад в валовой внутренний продукт;

- вклад в формирование доходов бюджета.

Предполагается, что:

- прямой финансовый вклад в валовой внутренний продукт определяется как прямое увеличение значения валового внутреннего продукта в результате реализации предлагаемых решений;

- репродуктивный и культурный вклад реализуется в будущих периодах и обеспечивает прирост валового внутреннего продукта в будущем. Соответственно, его влияние можно оценить как составляющую прогнозных темпов роста валового внутреннего продукта;

- текущий финансовый, репродуктивный и культурный вклад в валовой внутренний продукт генерирует соответствующий вклад в формирование бюджета в соответствии с текущей долей бюджета указанного уровня в валовом внутреннем продукте.

Вклад от реализации предлагаемых решений в доходы регионального бюджета (Д деляется как доля бюджета в валовом внутреннем продукте. По официальным статистическим данным, указанная доля составляет 14 процентов. Расчет производится по формуле:

$Д_{\phi б}=\mathrm{y}_{C \ni У} * 0,14$, млн.руб.

$$
\begin{aligned}
& Д_{\phi \sigma 1}=648,478^{*} 0,14=90,7869 \\
& Д_{\phi \sigma 2}=960,269^{*} 0,14=134,4377 \\
& Д_{\phi б 3}=1277,004^{*} 0,14=178,7806
\end{aligned}
$$

Выводы: при выполнении предлагаемых мероприятий предполагается укрепить устойчивую тенденцию снижения пожарных рисков, усовершенствовать интеграционные процессы в сфере противопожарного страхования жилья, создать эффективную систему мотивации для страхователей, повысить благоприятный климат для новых инвестиций.

Предусматриваемые затраты позволят сократить количество пожаров, предотвратить гибель при пожарах людей, снизить экономический ущерб от пожаров.

Расчеты показали, что величина эффекта по снижению социально-экономического ущерба $\left(\mathrm{Y}_{\text {сэу }}\right)$ при реализации предложенных мероприятий составит не менее 648,478 млн. рублей, а вклад от реализации предлагаемых решений в доходы бюджета субъекта (Д

Таким образом, можно с уверенностью сказать, что предполагаемая гипотеза, выдвигаемая в начале подтверждена.

Культура страхования в Российской Федерации должна иметь более значимый уровень пропаганды, и каждый гражданин России должен понимать значимость финансового образования.

\section{ЛИТЕРАТУРА}

1. Присяжнюк, Н.Л., О.В. Кружкова, Е.С. Кузнецова аnd Т.Н. Соловьева, 2019. Оценка ущерба от пожаров и ЧС: монография. Москва: Академия ГПС мЧС России.

2. Механизм противопожарного страхования как предупредительная мера по обеспечению пожарной безопасности / О.В. Кружкова, Е.С. Кузнецова, T.H. Соловьева // Chronos. - 2021. - T. 6. — № 6(56). — C. 36-39.

3. Постановление Правительства Российской Федерации «0 федеральной целевой программе «Пожарная безопасность в Российской Федерации на период до 2017 года»» от 30.12.2012 № 1481.

4. Постановление Правительства Российской Федерации «0 федеральной целевой программе «Снижение рисков и смягчение последствий чрезвычайных ситуаций природного и техногенного характера в Российской Федерации до 2015 года»» от 07.07.2011 № 555.

5. Пожары и пожарная безопасность в 2019 г. Статистический сборник ФГБУ ВНИИПО 2020 г. Date Views 10.06.2021 www.fireman.club 